\title{
An Evaluation of Northern Australian Wet Season Rainfall Bursts in CMIP5 Models
}

\author{
Sugata Narsey, Michael J. ReEder, AND Christian JaKOB \\ School of Earth, Atmosphere and Environment, Monash University, and Australian Research Council \\ Centre of Excellence for Climate Systems Science Clayton, Victoria, Australia \\ DUNCAN ACKERLEY \\ Met Office, Exeter, United Kingdom
}

(Manuscript received 24 September 2017, in final form 4 July 2018)

\begin{abstract}
The simulation of northern Australian wet season rainfall bursts by coupled climate models is evaluated. Individual models produce vastly different amounts of precipitation over the north of Australia during the wet season, and this is found to be related to the number of bursts they produce. The seasonal cycle of bursts is found to be poor in most of the models evaluated. It is known that northern Australian wet season bursts are often associated with midlatitude Rossby wave packets and their surface signature as they are refracted toward the tropics. The relationship between midlatitude waves and the initiation of wet season bursts is simulated well by the models evaluated. Another well-documented influence on the initiation of northern Australian wet season bursts is the Madden-Julian oscillation (MJO). No model adequately simulated the tropical outgoing longwave radiation temporal-spatial patterns seen in the reanalysis-derived OLR. This result suggests that the connection between the MJO and the initiation of northern Australian wet season bursts in models is poor.
\end{abstract}

\section{Introduction}

General circulation models (GCMs) are powerful tools for understanding the dynamical mechanisms involved in producing wet season rainfall in the tropics and for predicting future changes in such regions under various greenhouse warming scenarios. Therefore, the ability of these models to accurately, or at least adequately, simulate known aspects of the northern Australian wet season is of importance. The focus of this study is the sharp intraseasonal transitions of the northern Australian wet season from relatively dry conditions to relatively wet conditions commonly referred to as rainfall bursts (Troup 1961; Wheeler and McBride 2005). Here we choose to focus on the wetter part of the year (from October to April), rather than focusing solely on the monsoon season (typically from late December to March).

Rainfall bursts are generally defined by the accumulated precipitation (e.g., Troup 1961), or the change to deep low-level westerly winds with easterlies aloft

\footnotetext{
Corresponding author: Sugata Narsey, sugata.narsey@monash. edu
}

typical of the active phase of the monsoon (e.g., Drosdowsky 1996), or some combination of these two factors. However, in the present study we aim to investigate the dynamics governing the intraseasonal variability of the Australian wet season, that is, the transitions from dry (break) conditions to active (burst) conditions throughout the wet season. To do so we apply a definition of bursts that is based on the tendency of rainfall relative to the seasonal cycle (Berry and Reeder 2016). This method identifies bursts of rainfall that are large for the part of the season in which they occur. Our chosen definition of rainfall bursts conservatively captures approximately $70 \%$ of wet season rainfall in observations (not shown here). One advantage of this definition is that it is based only on area-averaged rainfall and makes no assumptions about the circulation to determine a rainfall burst. This avoids any implicit bias toward particular synoptic conditions and allows us to study patterns associated with rainfall more objectively.

A comparison of these events against the Troup (1961) definition of monsoon bursts for the historical record (not shown here) showed that the Berry and 
Reeder (2016) wet season rainfall bursts coincide with monsoon bursts during the peak monsoon season. During the premonsoon period these events are often smaller in magnitude.

Although the rainfall associated with these identified rainfall bursts may be larger during the peak wet season compared to the edges of the wet season, there is strong evidence to suggest that the dynamics governing the transitions from dry to wet are in fact essentially the same throughout the whole wet season (Berry and Reeder 2016; Narsey et al. 2017). The ability of coupled climate models to simulate the dynamics of these dry-towet transitions has yet to be evaluated and is the motivation for the present study.

The Intergovernmental Panel on Climate Change (IPCC) Fifth Assessment Report found that the skill of models in reproducing the climatological features of the global monsoon system has improved (Flato et al. 2013). These include improvements to the climatological rainfall pattern, the seasonal cycle of rainfall, and the variability of precipitation at both intraseasonal and interannual time scales (Sperber et al. 2013). On balance, it appears likely that the global monsoon system will strengthen in a warmer world, with earlier onsets and higher extreme precipitation (Christensen et al. 2013). However, regionally, and for rainfall over the tropical north of Australia in particular, the skill of models is low (Jourdain et al. 2013), and the climate change projections for the northern Australian wet season are highly variable (Moise et al. 2012; Brown et al. 2016).

Colman et al. (2011) evaluated the simulation of the Australian monsoon at the seasonal time scale in phase 3 of the Coupled Model Intercomparison Project (CMIP3) models. They found that while the multimodel mean had little climatological rainfall bias in the tropical north of Australia, there was a wide spread in individual model bias. Model rainfall biases were associated with both the spatial pattern of rainfall and the overall rainfall itself. In general, however, the models seemed to show physically plausible patterns of circulation change, with stronger low-level westerlies associated with greater rainfall. Brown et al. (2013) found that the next phase of climate models (CMIP5) showed an improvement in their simulation of the Australian monsoon climatology, although precipitation biases remained in individual models. They also found that the mean position of the monsoon shear line during January-February (the peak of the wet season) was well simulated by most of the CMIP5 models.

Rainfall over the north of Australia is often associated with the passage of the active phase of the Madden-Julian oscillation (MJO) over the Maritime Continent (e.g., McBride 1983; Holland 1986; Hendon and Liebmann
1990; Wheeler and McBride 2005; Wheeler et al. 2009). In an evaluation study of convectively coupled equatorial waves, Hung et al. (2013) found that although CMIP5 models generally simulated the MJO better than CMIP3 models, their simulation of the MJO remained poor. Out of 20 CMIP5 models, they found that only 1 realistically simulated the eastward propagation of the MJO, and most modeled MJOs had periods that were too long, resulting in more persistent precipitation over the tropics.

Midlatitude troughs are another important influence on the northern Australian wet season at intraseasonal time scales (Keenan and Brody 1988; Danielsen 1993; Davidson et al. 2007). Berry and Reeder (2016) showed that the initiation of northern Australian wet season bursts coincided with the passage of a midlatitude upper-level Rossby wave train-and its associated low-level front. Narsey et al. (2017) found that the initiation of approximately two-thirds of northern Australian wet season bursts are associated with such midlatitude systems.

In the present study we evaluate the dynamics of northern Australian wet season bursts in CMIP5 models. The data and methods used in this study are described in section 2. The statistics of bursts in CMIP5 models is described in section 3. A breakdown of the types of bursts that occur in CMIP5 models is described in section 4. Finally, the dynamics of the bursts in CMIP5 models is evaluated in section 5 , followed by a brief discussion and concluding remarks in section 6 .

\section{Data and methods}

\section{a. Data}

Observation-based reanalyses datasets are used to evaluate coupled climate model simulations of northern Australian wet season bursts over the period 1979-2005. Precipitation is evaluated against the Australian Water Availability Project (AWAP) daily rainfall dataset (Jones et al. 2009). This high-resolution $\left(0.05^{\circ} \times 0.05^{\circ}\right)$ dataset is available over Australian land areas. Outgoing longwave radiation (OLR) is evaluated using the daily NOAA interpolated outgoing longwave radiation dataset, which has a resolution of $2.5^{\circ} \times 2.5^{\circ}$ (Liebmann 1996). All other fields are derived from the European Centre for MediumRange Weather Forecasts interim reanalysis (ERAInterim), which is provided at a resolution of $0.75^{\circ} \times$ $0.75^{\circ}$ with time intervals of $6 \mathrm{~h}$ (Dee et al. 2011).

The 29 CMIP5 coupled climate models (Taylor et al. 2012) used in this study are listed in Table 1 . Daily data from the first ensemble member of the historical experiments are analyzed for each model. All composite analyses are done on each model's native grid, and the 
TABLE 1. Models used in this study from the CMIP5 archive with details taken from the CMIP5 website (http://cmip-pcmdi.llnl.gov/cmip5/ availability.html).

\begin{tabular}{|c|c|}
\hline Model(s) & Model host institution(s) \\
\hline ACCESS1.0 & $\begin{array}{l}\text { Commonwealth Scientific and Industrial Research Organisation, Australia (CSIRO), and Bureau of } \\
\text { Meteorology (Australia) (BoM) }\end{array}$ \\
\hline \multicolumn{2}{|l|}{ ACCESS1.3 } \\
\hline BCC_CSM1.1 & Beijing Climate Center, China Meteorological Administration \\
\hline \multicolumn{2}{|l|}{ BCC_CSM1.1(m) } \\
\hline BNU-ESM & College of Global Change and Earth System Science, Beijing Normal University \\
\hline CMCC-CESM & Centro Euro-Mediterraneo sui Cambiamenti Climatici \\
\hline \multicolumn{2}{|l|}{ CMCC-CM } \\
\hline \multicolumn{2}{|l|}{ CMCC-CMS } \\
\hline CNRM-CM5 & $\begin{array}{l}\text { Centre National de Recherches Météorologiques/Centre Europeen de Recherche et Formation Avancée en } \\
\text { Calcul Scientifique }\end{array}$ \\
\hline CSIRO Mk3.6.0 & $\begin{array}{l}\text { Commonwealth Scientific and Industrial Research Organisation in collaboration with the Queensland } \\
\text { Climate Change Centre of Excellence }\end{array}$ \\
\hline CanESM2 & Canadian Centre for Climate Modelling and Analysis \\
\hline FGOALS-g2 & LASG, Institute of Atmospheric Physics, Chinese Academy of Sciences; and CESS, Tsinghua University \\
\hline \multicolumn{2}{|r|}{ 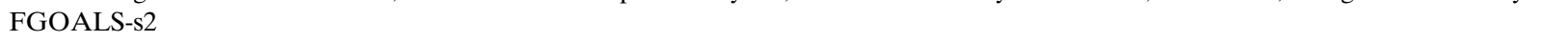 } \\
\hline GFDL CM3 & Geophysical Fluid Dynamics Laboratory \\
\hline \multicolumn{2}{|l|}{ GFDL-ESM2G } \\
\hline \multicolumn{2}{|l|}{ GFDL-ESM2M } \\
\hline HadGEM2-CC & Met Office Hadley Centre \\
\hline INM-CM4.0 & Institute of Numerical Mathematics \\
\hline IPSL-CM5A-LR & L'Institut Pierre-Simon Laplace \\
\hline \multicolumn{2}{|l|}{ IPSL-CM5A-MR } \\
\hline \multicolumn{2}{|l|}{ IPSL-CM5B-LR } \\
\hline MIROC-ESM & $\begin{array}{l}\text { Japan Agency for Marine-Earth Science and Technology, Atmosphere and Ocean Research Institute (The } \\
\text { University of Tokyo), and National Institute for Environmental Studies }\end{array}$ \\
\hline \multicolumn{2}{|l|}{ MIROC-ESM-CHEM } \\
\hline MIROC5 & $\begin{array}{l}\text { Atmosphere and Ocean Research Institute (The University of Tokyo), National Institute for Environmental } \\
\text { Studies, and Japan Agency for Marine-Earth Science and Technology }\end{array}$ \\
\hline MPI-ESM-LR & Max Planck Institute for Meteorology (MPI-M) \\
\hline \multicolumn{2}{|l|}{ MPI-ESM-MR } \\
\hline MRI-CGCM3 & Meteorological Research Institute \\
\hline \multicolumn{2}{|l|}{ MRI-ESM1 } \\
\hline NorESM1-M & Norwegian Climate Centre \\
\hline
\end{tabular}

final results are regridded to a common $2.5^{\circ} \times 2.5^{\circ}$ grid for the purpose of evaluation and calculating multimodel means.

\section{b. Diagnosing bursts}

We define northern Australian wet season bursts in CMIP5 models and the reanalyses using the method of Berry and Reeder (2016) as follows: Daily precipitation is averaged over the land areas in the north of Australia $\left(10^{\circ}-20^{\circ} \mathrm{S}, 120^{\circ}-150^{\circ} \mathrm{E}\right)$ for the period $1979-2005$. A climatology is calculated for the day-of-the-year mean and standard deviation. These climatology time series are then smoothed using a 60-day low-pass filter and are used to define the mean annual cycle of rainfall and daily variability, respectively. A burst is identified when the daily rainfall increases from below half a standard deviation from the annual cycle to above half a standard deviation within a 7-day period. The day on which rainfall exceeds the upper threshold is designated as day
0 of the burst event. Bursts are only diagnosed during the wetter part of the year (October-April). Examples of identified bursts can be found in Figs. 1 of Berry and Reeder (2016) and Narsey et al. (2017).

\section{c. Categorizing bursts}

Bursts can be usefully categorized into those associated with midlatitude disturbances and those that are associated with tropical disturbances. Following Narsey et al. (2017), this distinction can be made using the circulation tendency. Here, we use a slightly modified form of that described by Narsey et al. (2017), which is outlined now.

The circulation tendency in a bounded region on an isobaric surface is equal to the horizontal convergence of absolute vorticity flux through the boundaries as stated in Eq. (1) (Raymond et al. 2014; Haynes and McIntyre 1987). Narsey et al. (2017) calculated the lowlevel vertically integrated (from 1000 to $850 \mathrm{hPa}$ ) 
circulation tendency; however, because of the resolution of the available CMIP5 model data, we choose to calculate the circulation tendency on the $850-\mathrm{hPa}$ isobaric surface instead $\left(d \Gamma_{850} / d t\right)$. The results using the $850-\mathrm{hPa}$ circulation tendency were found to be similar to the 1000-850-hPa vertically integrated circulation tendency in the reanalysis data (not shown). As such, the circulation tendency on the $850-\mathrm{hPa}$ isobaric surface within a closed circuit $C$ is

$$
\frac{d \Gamma_{850}}{d t}=-\oint_{C} \mathbf{Z}_{850} \cdot \hat{\mathbf{n}} d S,
$$

where

$$
\mathbf{Z}_{850}=\mathbf{u}_{h}\left(\zeta_{p}+f\right)-\omega \zeta_{h}+\mathbf{k} \wedge \mathbf{F}_{\text {fri }} .
$$

In Eq. (1), $\Gamma_{850}$ is the circulation on the $850-\mathrm{hPa}$ isobaric surface, $\mathbf{Z}_{850}$ is the horizontal flux of absolute vorticity $\left(\mathrm{m} \mathrm{s}^{-2}\right)$, and $\hat{\mathbf{n}}$ is the unit outward normal along the path $C$. In Eq. (2), $\mathbf{u}_{h}$ is the horizontal wind vector, $\zeta_{p}$ is the vertical vorticity on an isobaric surface, $f$ is the planetary vorticity, $\omega$ is the vertical motion in pressure coordinates, $\boldsymbol{\zeta}_{h}$ is the horizontal vorticity vector, $\mathbf{k}$ is the unit vector in the vertical direction, and $\mathbf{F}_{\text {fri }}$ is related to the friction.

The three contributions to $\mathbf{Z}_{850}$ [rhs of Eq. (2)] are the advective flux of the vertical component of absolute vorticity, the vorticity flux associated with vortex tilting, and a vorticity flux associated with friction, respectively. Although it is often large on the scale of individual clouds, the second term is found to be small for the areaaveraged tropical north of Australia (Narsey et al. 2017) and consequently neglected. The third term is assumed to be small, particularly on the $850-\mathrm{hPa}$ level, away from the surface and is also neglected.

The direction from which bursts are most strongly influenced is determined according to the boundary from which the absolute vorticity flux correlates best with the total circulation tendency. This is not necessarily the same as the direction of largest absolute vorticity flux. In this study we multiply the vorticity by -1 so that a cyclonic circulation tendency is positive.

\section{The statistics of bursts in models}

The simulation of northern Australian wet season bursts is evaluated for each model against the reanalyses. Table 2 lists these evaluation metrics calculated for each model, based on particular features of rainfall bursts thought to be of importance. Each metric is given equal weighting and the models are sorted by average ranking from best performing (top) to worst performing (bottom). No model consistently ranks highest for all metrics. These metrics are individually described where relevant in the following sections.

Figure 1 shows the smoothed seasonal cycle of daily precipitation and daily standard deviation of precipitation calculated from the AWAP rainfall dataset and for CMIP5 models. The multimodel mean closely resembles observations, although the early wet season is slightly too low and the late wet season is too high for both daily precipitation (by approximately $1 \mathrm{~mm} \mathrm{day}^{-1}$ ) and daily standard deviation (by less than $1 \mathrm{~mm} \mathrm{day}^{-1}$ ). However, individual models vary greatly in both the magnitude of precipitation (Table 2) and the magnitude of daily variability. The timing of the wet season peak is also highly variable in models, with several occurring up to one month too early or one month too late. The observed seasonal cycle is asymmetric, with a gradual increase in precipitation during the premonsoon period (from November to December) and a sharp decrease at the end of the season in March. Many models capture this pattern of precipitation (Fig. 1); however, there are several that have an overly symmetrical seasonal cycle in precipitation.

Rainfall bursts are defined relative to the seasonal cycle of precipitation for each model. Although the amount of precipitation associated with a burst can vary greatly between models, and even within a wet season, defining bursts in this manner is an objective way to determine the influences on burst initiation in models.

The number of bursts and the interannual variability of bursts is plotted in Fig. 2. The number of bursts diagnosed from observations is remarkably consistent from year to year at about seven bursts per year with a standard deviation of less than two. The majority of models have more bursts than this, as well as a larger interannual variability in burst numbers. The interannual standard deviation of bursts is weakly correlated $(r=$ $0.50)$ to the average number of bursts per season.

Figure 3 shows the total number of bursts diagnosed for AWAP and CMIP5 models in the period 19792005 plotted against the average daily wet season rainfall. Models with more bursts tend to produce more rainfall (Table 2), although the relationship is weak $(r=0.34)$.

Figure 4 shows the seasonal cycle of monthly burst counts for AWAP and CMIP5 models. The number of diagnosed bursts shows a seasonal cycle, with more bursts diagnosed in the premonsoon phase (from November to December) than the peak monsoon (from January to February). The multimodel mean has a similar peak in November, although there are too many bursts late in the wet season and too few in the early wet season. As with the seasonal cycle of daily precipitation, 
TABLE 2. Evaluation metrics calculated for each model. The metrics (respectively) are the average wet season rainfall (Pr; mm), the number of diagnosed bursts between 1979 and 2005 (nbursts), the correlation of model burst count seasonal cycle with reanalysis burst count seasonal cycle $\left[r\right.$ (burst $\left.\left._{\text {seas }}\right)\right]$, the correlation of model southerly vorticity flux burst mean with that from reanalysis $\left[r\left(\zeta_{\text {as }}\right)\right]$, the RMSE of model 250-hPa zonal wind burst mean with that from reanalysis [RMSE(U250)], the RMSE of 250-hPa meridional wind anomaly burst mean with that from reanalysis [RMSE $\left.\left(\mathrm{V} 250^{\prime}\right)\right]$, the RMSE of model MSLP anomaly burst mean with that from reanalysis $\left[\operatorname{RMSE}\left(\mathrm{MSLP}^{\prime}\right)\right]$, and the correlation of model OLR anomaly Hovmöller plots with that from reanalysis $\left[r\left(\mathrm{OLR}_{\text {hov }}^{\prime}\right)\right]$. With the exception of the OLR anomalies, all other spatial metrics are calculated for the burst composite at two days prior to the burst for the region $60^{\circ} \mathrm{S}-$ $10^{\circ} \mathrm{N}, 80^{\circ} \mathrm{E}-180^{\circ}$. The models are sorted by the average ranking from best performing (top) to worst performing (bottom).

\begin{tabular}{|c|c|c|c|c|c|c|c|c|}
\hline Model & $\operatorname{Pr}$ & nbursts & $r\left(\right.$ burst $\left._{\text {seas }}\right)$ & $r\left(\zeta_{\mathrm{as}}\right)$ & RMSE(U250) & RMSE(V250') & RMSE(MSLP') & $r\left(\mathrm{OLR}_{\mathrm{hov}}^{\prime}\right)$ \\
\hline OBS & 794 & 190 & - & - & - & - & - & - \\
\hline GFDL CM3 & 1007 & 198 & 0.92 & 0.87 & 3.76 & 0.94 & 38.87 & 0.02 \\
\hline GFDL-ESM2M & 1099 & 176 & 0.97 & 0.88 & 2.76 & 1.03 & 43.38 & -0.14 \\
\hline ACCESS1.0 & 527 & 196 & 0.83 & 0.5 & 2.47 & 1.2 & 46.42 & -0.05 \\
\hline ACCESS1.3 & 701 & 195 & 0.35 & 0.85 & 2.78 & 1.39 & 56.36 & 0.05 \\
\hline MPI-ESM-LR & 779 & 276 & -0.11 & 0.88 & 3.87 & 1.04 & 53.76 & 0.1 \\
\hline CSIRO Mk3.6.0 & 967 & 199 & -0.31 & 0.84 & 3.15 & 1.06 & 49.65 & 0 \\
\hline FGOALS-s2 & 861 & 230 & 0.69 & 0.54 & 5.58 & 1.23 & 53.81 & 0.12 \\
\hline MRI-ESM1 & 913 & 234 & 0.18 & 0.96 & 3.34 & 1.01 & 43.13 & -0.17 \\
\hline MRI-CGCM3 & 895 & 225 & -0.21 & 0.66 & 3.4 & 1.07 & 43.23 & -0.03 \\
\hline BCC_CSM1.1(m) & 836 & 222 & 0.72 & 0.42 & 2.93 & 1.26 & 55.83 & -0.17 \\
\hline GFDL-ESM2G & 1343 & 222 & 0.66 & 0.86 & 2.79 & 0.98 & 55.06 & -0.33 \\
\hline CNRM-CM5 & 903 & 213 & 0.79 & 0.51 & 3.34 & 1.78 & 75.55 & 0.08 \\
\hline NorESM1-M & 1343 & 231 & 0.72 & 0.96 & 2.67 & 1.35 & 51.11 & -0.3 \\
\hline CMCC-CM & 400 & 267 & 0.81 & 0.48 & 3.91 & 1.14 & 47.97 & 0.01 \\
\hline MPI-ESM-MR & 849 & 252 & 0.3 & 0.17 & 4.62 & 1.01 & 61.83 & 0.18 \\
\hline FGOALS-g2 & 1048 & 233 & 0.48 & 0.44 & 4.94 & 0.79 & 38.67 & -0.12 \\
\hline HadGEM2-CC & 449 & 202 & 0.57 & -0.2 & 3.17 & 1.34 & 56.3 & 0.07 \\
\hline CMCC-CMS & 532 & 232 & 0.05 & 0.45 & 3.83 & 1.24 & 56.19 & -0.01 \\
\hline IPSL-CM5A-MR & 334 & 186 & 0.54 & 0.51 & 4.85 & 1.31 & 69.63 & -0.11 \\
\hline IPSL-CM5B-LR & 596 & 152 & 0.52 & 0.32 & 4.91 & 1.45 & 67.11 & 0.05 \\
\hline IPSL-CM5A-LR & 325 & 165 & 0.65 & 0.87 & 6.92 & 1.49 & 100.42 & 0.02 \\
\hline MIROC-ESM & 1094 & 277 & 0.8 & 0.73 & 6.83 & 1.28 & 61.13 & -0.09 \\
\hline BNU-ESM & 660 & 121 & 0.19 & -0.12 & 4.96 & 1.22 & 59.46 & 0.04 \\
\hline CanESM2 & 532 & 189 & -0.26 & 0.34 & 2.82 & 1.58 & 72.41 & -0.1 \\
\hline CMCC-CESM & 809 & 314 & 0.58 & -0.33 & 7.44 & 1.31 & 62.32 & 0.04 \\
\hline MIROC5 & 1334 & 248 & 0.58 & 0.8 & 4.18 & 1.33 & 55.1 & -0.17 \\
\hline MIROC-ESM-CHEM & 1108 & 281 & 0.6 & 0.43 & 6.19 & 1.28 & 55.02 & -0.06 \\
\hline BCC_CSM1.1 & 1098 & 230 & 0.52 & 0.15 & 4.12 & 1.35 & 65.44 & -0.05 \\
\hline INM-CM4 & 780 & 146 & -0.3 & -0.39 & 3.62 & 1.8 & 90.32 & -0.03 \\
\hline
\end{tabular}

the CMIP5 models have large differences in simulating the seasonal cycle of bursts, with many models peaking in the wrong months. The Pearson correlation of monthly counts of bursts between models and observations is listed in Table 2, with values ranging from -0.31 to 0.97 .

\section{Types of bursts in models}

Narsey et al. (2017) found that northern Australian wet season bursts coincide with a rapid increase in the convergence of absolute vorticity flux and therefore an associated rapid increase in the circulation tendency. Figure 5 shows the time-lag composite around rainfall bursts of the convergence of absolute vorticity flux (at $850 \mathrm{hPa}$ ) for CMIP5 models as well as for the reanalysis. The multimodel mean correctly exhibits the total change in circulation tendency, although the cyclonic increase in circulation is weaker than in the reanalysis before the burst, and too strong after the burst begins. This result is consistent between individual models, with the cyclonic increase in circulation too weak before the burst and too strong after the burst begins for 28 out of 29 models.

In the reanalysis the time evolution of the circulation tendency anomaly is most strongly related to the absolute vorticity flux through the southern boundary. The correlation of absolute vorticity flux anomalies through the southern boundary between model composites and reanalysis composites is listed in Table 2. Although some models accurately reproduce the observed pattern, the magnitude of the change in absolute vorticity flux through the southern boundary is underestimated in the multimodel mean. The changes through the eastern and western boundaries are also underestimated in the multimodel mean. In contrast to this, the change in absolute vorticity flux through the northern boundary is 

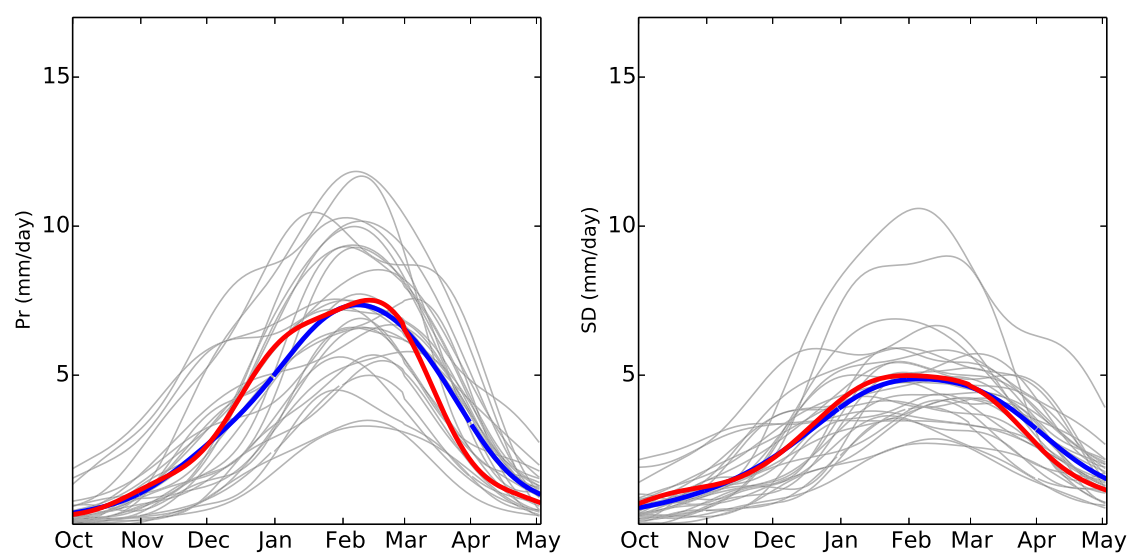

FIG. 1. The smoothed seasonal cycle of day-of-the-year mean (left) precipitation and (right) standard deviation for individual models (light gray lines), the multimodel mean (thick blue line), and the AWAP observation-based dataset (red line). Rainfall is averaged over the land area within the tropical north of Australia for the period 1979-2005.

overestimated in several models, and this is reflected in the multimodel mean.

Figure 6 shows the time-lag composite of moisture flux convergence anomalies (at $850 \mathrm{hPa}$ ) for the CMIP5 models and the reanalysis. The composite is constructed in the same way as that for the circulation tendency. The increase of moisture flux convergence around the composite burst at day 0 is too strong in almost all models and this is reflected in the multimodel mean. As with absolute vorticity flux, the change in moisture flux through the southern, eastern, and western boundaries is in general too weak in the models. The moisture flux through the northern boundary is too strong in most models, and this is seen in the multimodel mean.

Although the CMIP5 models show some biases in circulation tendency, in general they correctly simulate the temporal pattern associated with the initiation of rainfall bursts found in the reanalysis. We now consider the types of bursts [i.e., northerly, easterly, southerly, and westerly types, as defined by Narsey et al. (2017)] that occur in each model. The categorization of bursts is done by correlating the flux of absolute vorticity through each boundary of our study region with the total circulation tendency. A burst is categorized as the direction giving the highest correlation [described in detail by Narsey et al. (2017)]. Figure 7 shows boxplots of the counts of bursts in each model separated by burst category, as well as proportions of bursts in each model (again by burst category), for CMIP5 models (shown as colored box, whiskers, and outliers) and the reanalysis (shown as black circles) for 1979-2005. Although the models produce a similar number of southerly flux (SF)type bursts compared to the reanalysis, they consistently produce too many of the other types of bursts [northerly flux (NF), easterly flux (EF), and westerly flux (WF) types]. As a result, the proportion of bursts categorized as southerly is generally too low, while the proportion of other categories of bursts is too high.

Figure 8 shows the normalized distribution of $\log _{10}$ precipitation for SF-type bursts, non-SF-type bursts, and nonburst days for CMIP5 models and reanalysis. The amount of precipitation associated with SF-type bursts in the reanalysis is similar to other bursts, although skewed to slightly lower rainfall. The multimodel mean

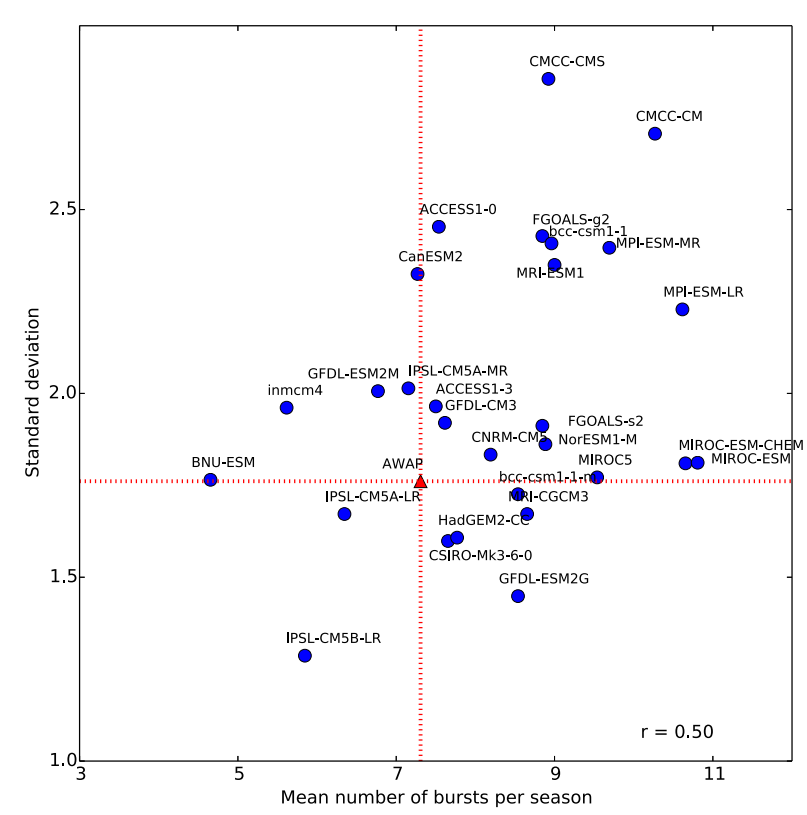

FIG. 2. The interannual variability of bursts is shown by the number of bursts per year vs the standard deviation in the number of bursts per year for individual models (blue circles) and AWAP (red triangle). 


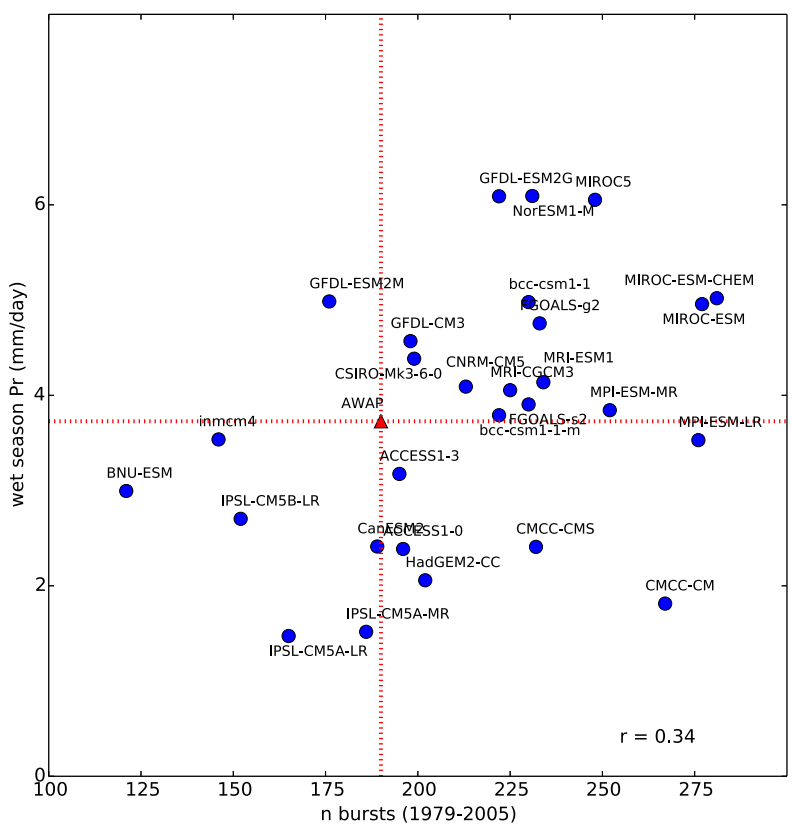

FIG. 3. The number of bursts vs the daily average wet season precipitation for individual models (blue circles) and AWAP (red triangle)

of the CMIP5 models exhibits similar behavior, with SF-type bursts skewed toward slightly lower rainfalls than other bursts. The shape of the distributions for individual models is highly variable, although in most models the SF burst distribution is skewed toward slightly lower rainfalls than the distribution for all other burst categories. The nonburst days distributions are skewed toward lower values in both reanalyses and CMIP5 models.

\section{The dynamics of burst types in models}

The previous section categorized rainfall bursts into those associated with midlatitude disturbances (SF-type bursts) and those associated with tropical disturbances (non-SF-type burst). The mean synoptic patterns for these two categories are now calculated for the reanalyses and the CMIP5 models.

Figure 9 shows the lag composite of the meridional wind anomaly at $250 \mathrm{hPa}$ two days prior to the burst, composited for the reanalysis and models. The composites are separated into SF-type bursts and nonSF-type bursts, and for the multimodel mean, stipples indicate agreement between at least $80 \%$ of models on the sign of the anomaly field. The SF-type bursts in the reanalysis are strongly related to upper-level midlatitude wave activity, with a wave train extending from the southern Indian Ocean and refracting slightly equatorward into the South Pacific two days prior to the composite burst. This pattern is remarkably consistent in the multimodel mean, with more than $80 \%$ of models in agreement two days prior to the composite burst.

The non-SF-type bursts also show a midlatitude wave pattern prior to the composite burst in the reanalysis, albeit weaker, with the disturbance oriented more northwest to southeast. This pattern is also found in the multimodel mean non-SF composite. Although the multimodel mean pattern is weaker than in the reanalysis, the agreement between models on the direction of meridional wind anomalies is also strong in the locations one would associate with a midlatitude wave pattern.

For each model, the root-mean-square error (RMSE) for the composite of meridional wind anomalies from all bursts (at day -2) compared to the reanalysis is listed in Table 2. RMSE is calculated over the region $60^{\circ} \mathrm{S}-10^{\circ} \mathrm{N}$, $80^{\circ} \mathrm{E}-180^{\circ}$. All CMIP5 models have an RMSE of less than $2 \mathrm{~m} \mathrm{~s}^{-1}$, while the anomalies in the reanalysis composite are greater than $7 \mathrm{~m} \mathrm{~s}^{-1}$.

The lag composite of mean sea level pressure two days prior to the burst is shown for the reanalysis and the multimodel mean in Fig. 10. Again, the composites are calculated separately for SF- and non-SF-type bursts. In the reanalysis SF composite two days prior to the burst, a midlatitude trough lies over the Australian continent extending toward the tropics, with a broad ridge extending from the southern Indian Ocean toward the west coast of Australia. A high pressure (anticyclonic) anomaly lies to the southeast of Australia over the southern parts of New Zealand.

The multimodel mean shows a similar pattern with a midlatitude trough over the Australian continent and a ridge over the west coast of Australia. However, the ridge to the west does not extend as far westward into the southern Indian Ocean, and a low pressure (cyclonic) anomaly is found instead at longitudes of $60^{\circ}-80^{\circ} \mathrm{E}$. More than $80 \%$ of models agree on this pattern, although it is different from the pattern found in the reanalysis composite. The anticyclonic anomaly found to the southeast of Australia in the reanalysis SF composite is weak in the multimodel mean SF composite, with low agreement between models.

The non-SF composite for the reanalysis shows a low pressure anomaly over the north of Australia extending into the tropics at two days prior to the burst. A high pressure anomaly lies to the southeast of Australia, extending into the southern central Pacific Ocean. The multimodel mean non-SF composite also shows a low pressure anomaly over the north of Australia extending into the tropics two days prior to the burst. However, although more than $80 \%$ of models agree on the sign of the mean sea level pressure (MSLP) anomaly, the 

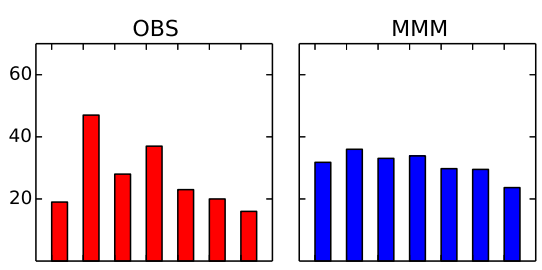

ACCESS1-0

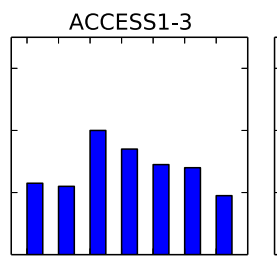

bcc-csm1-1
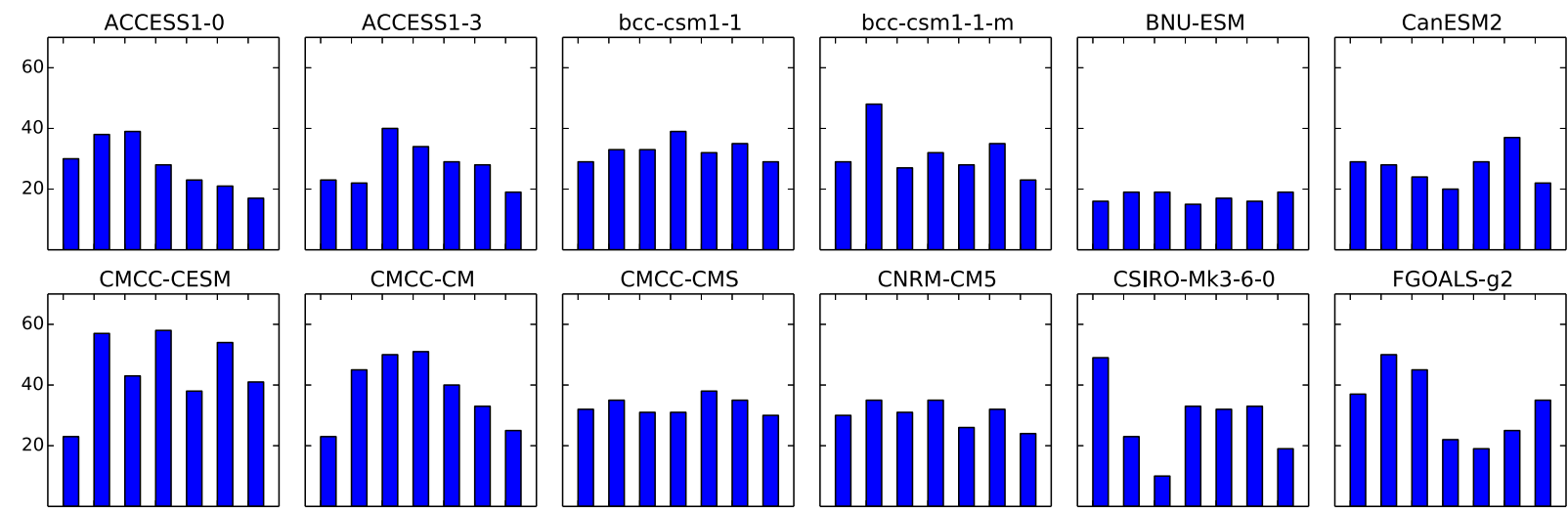

CNRM-CM5

CSIRO-Mk3-6-0
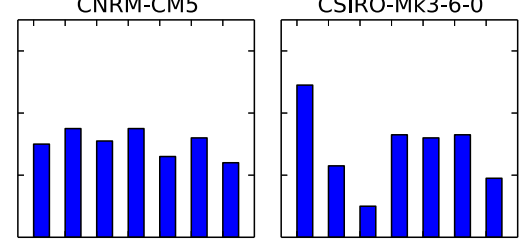

FGOALS-g2

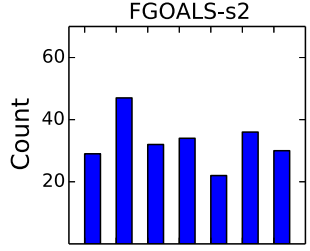

GFDL-CM3

GFDL-ESM2G

GFDL-ESM2M

HadGEM2-CC
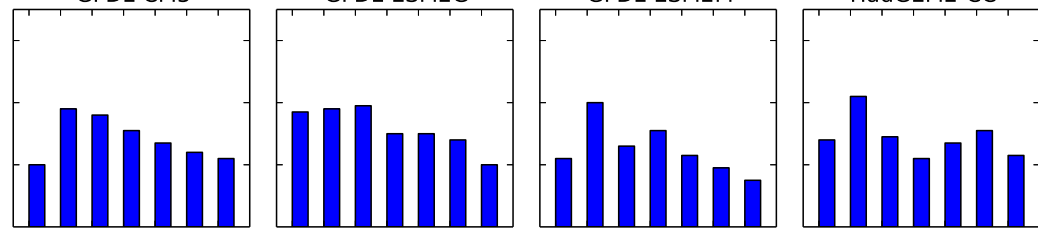

MIROC-ESM-CHEM

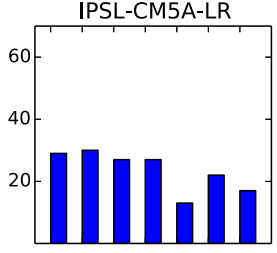

IPSL-CM5A-MR

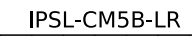

MIROC-ESM

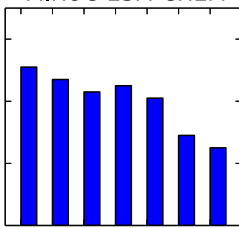

NorESM1-M
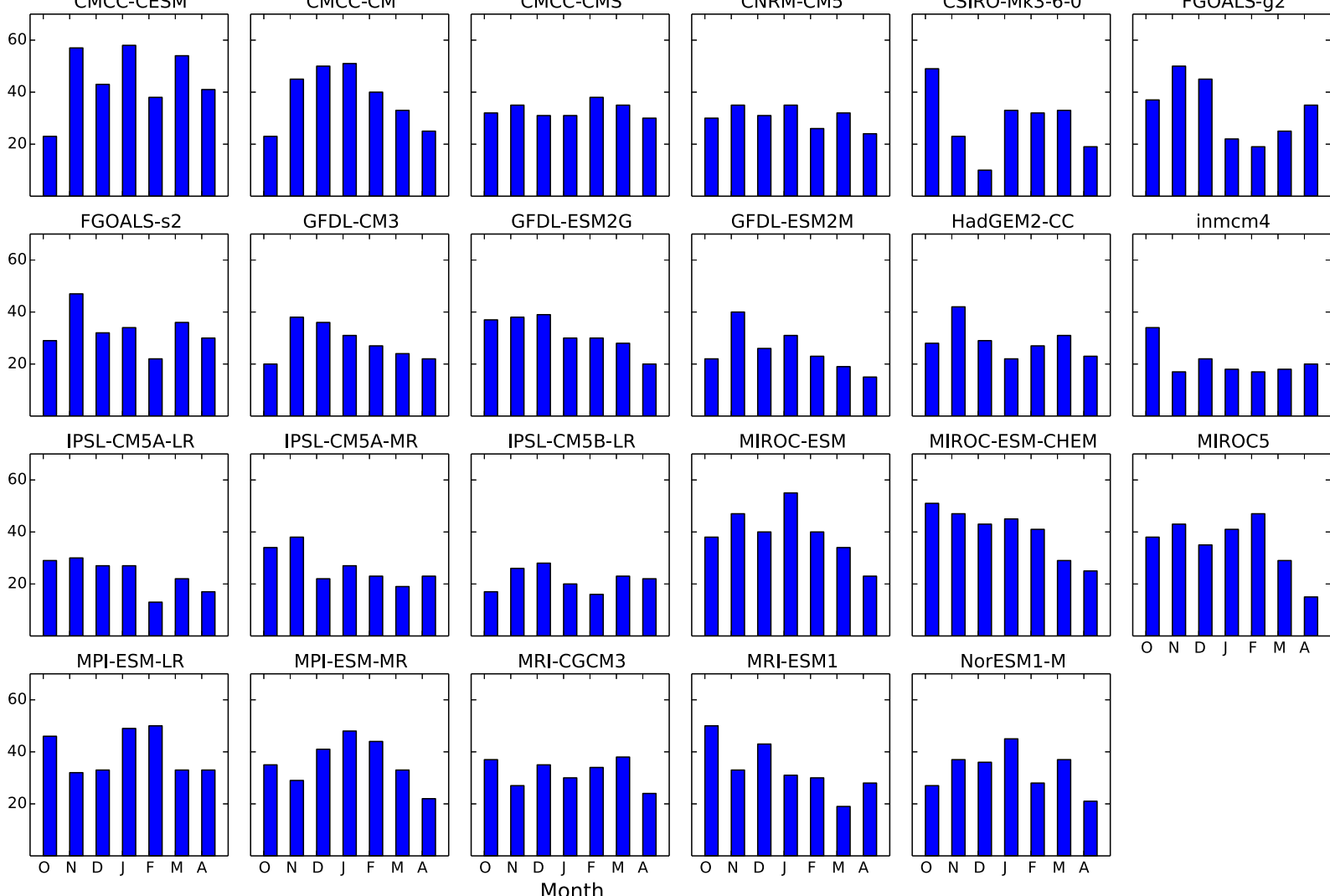

inmcm4

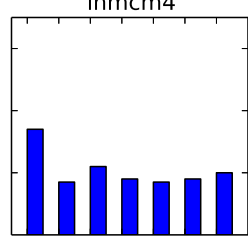

MIROC5

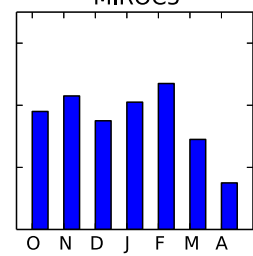

FIG. 4. The seasonal cycle of burst counts by month is shown for AWAP (OBS), the multimodel mean (MMM), and all individual models.

magnitude is too small (typically less than $30 \mathrm{~Pa}$ ). The models show strong agreement for the high pressure anomaly to the southeast of Australia, although this does not extend far into the southern Pacific. The models also show strong agreement on a weak high pressure anomaly over the west coast of Australia, although this is not present (or is weak) in the non-SF reanalysis composite.

For each model, the RMSE for the composite of MSLP anomalies from all bursts (at day -2) compared to the reanalysis is listed in Table 2. RMSE ranges from approximately 40 to $100 \mathrm{~Pa}$, while the anomalies in the reanalysis composite are greater than $200 \mathrm{~Pa}$.

Hovmöller plots for the time-lag composite of OLR anomalies for bursts in the reanalysis as well as the multimodel mean are plotted in Fig. 11. OLR anomalies are meridionally averaged between $10^{\circ} \mathrm{S}$ and $10^{\circ} \mathrm{N}$. The composites are once again calculated separately for SF- and non-SF-type bursts. The SF composite for the reanalysis shows a weak eastwardpropagating negative OLR anomaly reaching the longitudes of the tropical north of Australia around 

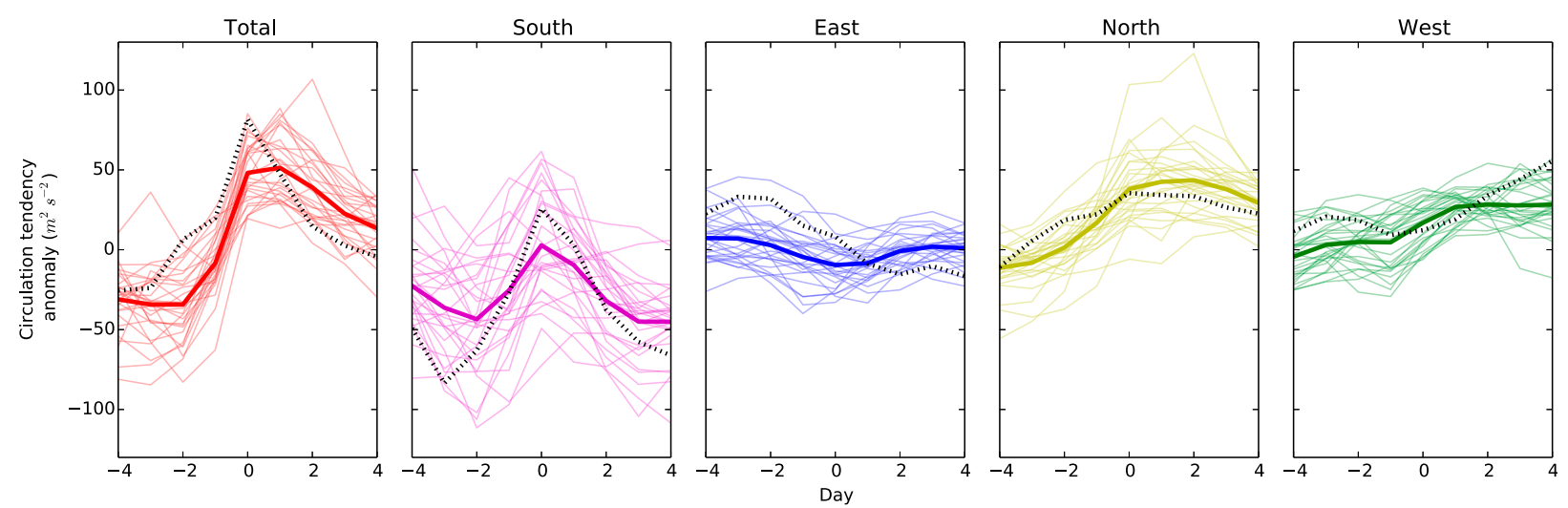

FIG. 5. Time-lag composites of the 850-hPa anomalous convergence of absolute vorticity flux (or circulation tendency anomaly) for all rainfall bursts decomposed by direction (where SF, EF, NF, and WF are shown in magenta, blue, yellow, and green, respectively), as well as the total circulation tendency anomaly (red). Individual models are shown as thin colored lines, and the multimodel mean is shown as thick colored lines. The composite for the ERA-Interim is also shown in each plot (dashed black lines).

the day of the burst. This pattern is not found (or is weak) in the multimodel mean SF composite, and models do not agree on the sign of the OLR anomalies. The non-SF composite for the reanalysis shows a very strong eastward-propagating negative OLR anomaly, which reaches the tropical north of Australia around the day of the composite burst. Again, this pattern is not found (or is weak) in the multimodel mean, and the models do not agree on the sign of the OLR anomalies. A weaker westward-propagating negative OLR anomaly is seen in the SF-type burst composite for the reanalysis, coinciding with the eastward-propagating negative OLR anomaly at day 0 .

For each model, the Hovmöller diagram of the composite of OLR for all bursts is correlated with that from reanalysis (listed in Table 2). No models perform well in reproducing OLR anomaly Hovmöller burst composite patterns from reanalysis, with the correlations ranging from -0.33 to 0.18 .

\section{Discussion and conclusions}

The aim of the present study was to investigate the dynamics governing the intraseasonal variability of the Australian wet season, that is, the transitions from dry (break) conditions to active (burst) conditions, and evaluate these features in climate models. We used the results of 29 CMIP5 models and objectively identified rainfall bursts in each model. The statistics of bursts in the models were evaluated before identifying and evaluating dynamical features of the northern Australian wet season intraseasonal variability in those models.

As noted by Brown et al. (2016), the multimodel mean seasonal cycle of precipitation in the tropical north of Australia is similar to observations, albeit with a slight overestimation in the late monsoon season (less than $\left.1 \mathrm{~mm} \mathrm{day}^{-1}\right)$. However, this similarity masks the large variability (up to $4 \mathrm{~mm} \mathrm{day}^{-1}$ ) in the amount of precipitation between models (Fig. 1). Similarly, the daily variability in the multimodel mean closely resembles
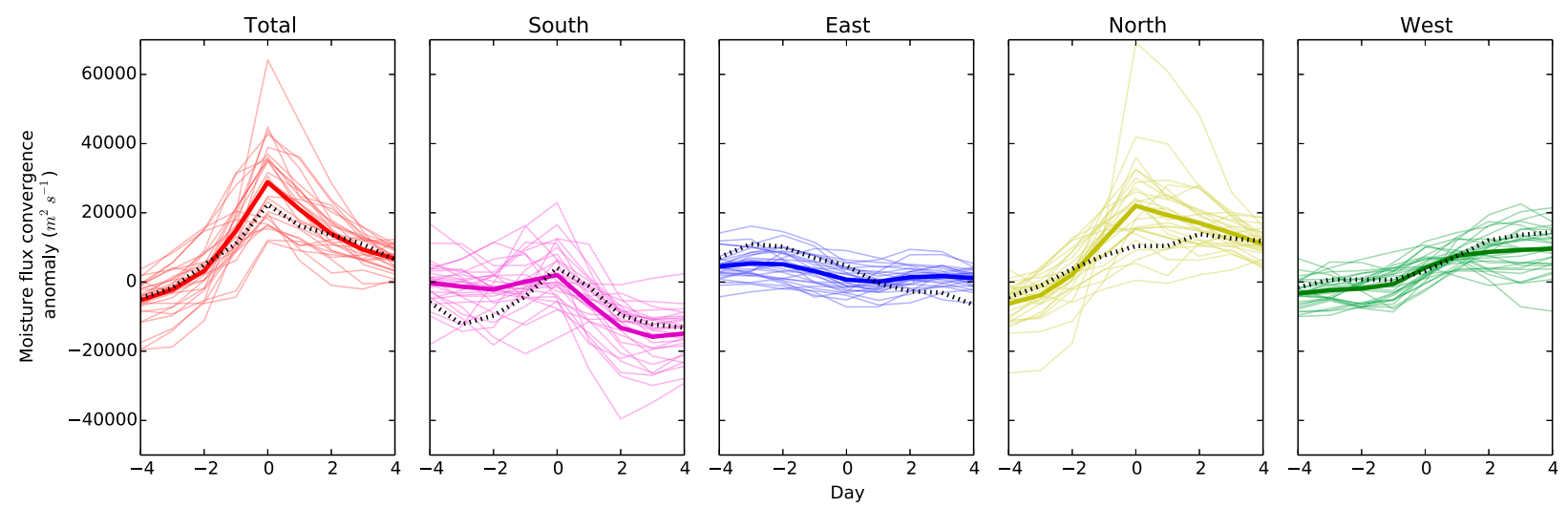

FIG. 6. As in Fig. 5, but for the 850-hPa moisture flux convergence anomaly. 

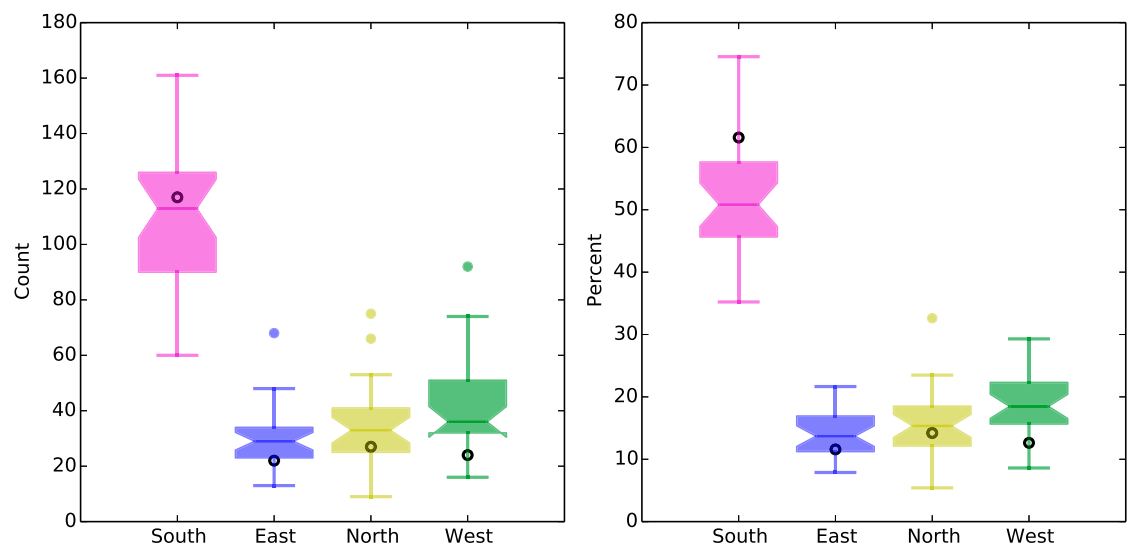

FIG. 7. Boxplots showing (left) the number of bursts and (right) the proportion of bursts in each category. The respective values from observations are shown as a black circle over each boxplot.

that from observations, although the intermodel spread is large. Most models have a seasonal peak in precipitation similar to the observed precipitation, although some peak too early (January) and others too late (March).

Many of the models evaluated produce too many bursts (up to $50 \%$ too many), and the number of bursts is typically too variable from year to year (up to twice the standard deviation; Fig. 2). In general, models with more bursts produce more wet season precipitation (Fig. 3). That CMIP5 models generally produce a number of bursts per year comparable to observations is consistent with the results of Brown et al. (2017), who showed that variability at less-than-interannual time scales in CMIP5 models was similar to the variability calculated from observations.

The seasonal cycle of bursts is not well represented in individual models, although the multimodel mean agrees well with the seasonal cycle of bursts from observations (Fig. 4).

Although the CMIP5 models have biases in the number and timing of bursts, they correctly simulate (to a varying degree) the circulation and moisture tendency patterns seen in the reanalysis (Figs. 5 and 6). The prominent role of the observed absolute vorticity flux through the southern boundary is weaker in the multimodel mean, and the change in moisture and vorticity fluxes through the northern boundary is too large.

The categorization of bursts in models proves to be insightful, with approximately three-quarters of the models simulating too many of the northerly flux (NF), easterly flux (EF), and westerly flux (WF) bursts. In contrast, the median of the CMIP5 models simulation of southerly flux (SF) bursts was similar to the observed (Fig. 7). As found in observations, the amount of precipitation produced by the SF-type and non-SF-type bursts is similar in models, although the shapes of the rainfall distributions between the models vary strongly (Fig. 8).

Upper-level midlatitude troughs are known to be associated with convection over northern Australia during the summer monsoon season (Keenan and Brody 1988). The midlatitude influence on SF-type bursts highlighted by Narsey et al. (2017) is simulated well in CMIP5 models, with most models showing an upperlevel Rossby wave train prior to the composite burst (Fig. 9) and an associated midlatitude trough near the surface (Fig. 10). The large-scale circulation pattern of the Southern Hemisphere and its associated variability is generally well represented in coupled climate models, for example, the spatial pattern of the midlatitude jet (e.g., Raphael and Holland 2006). The strength and consistency of the midlatitude wave pattern associated with the composite burst in CMIP5 models suggests that the observed teleconnection between midlatitude troughs and northern Australian wet season bursts is reproduced well by the models. This is an important finding, since climate change projections of the midlatitude storm track and the eddy-driven jet will likely have implications for changes to the intraseasonal variability of the northern Australian wet season. Berry and Reeder (2016) found that the distribution of the southern annular mode (SAM) index is positively skewed for northern Australian wet season bursts, implying a poleward shift in the storm track during bursts. Projected changes to the southern annular mode could therefore influence the variability of northern Australian wet season bursts. This link will be investigated in a future study.

The OLR composite of SF-type bursts in reanalysis (Fig. 11) suggests a possible influence of westwardpropagating tropical disturbances in conjunction with 

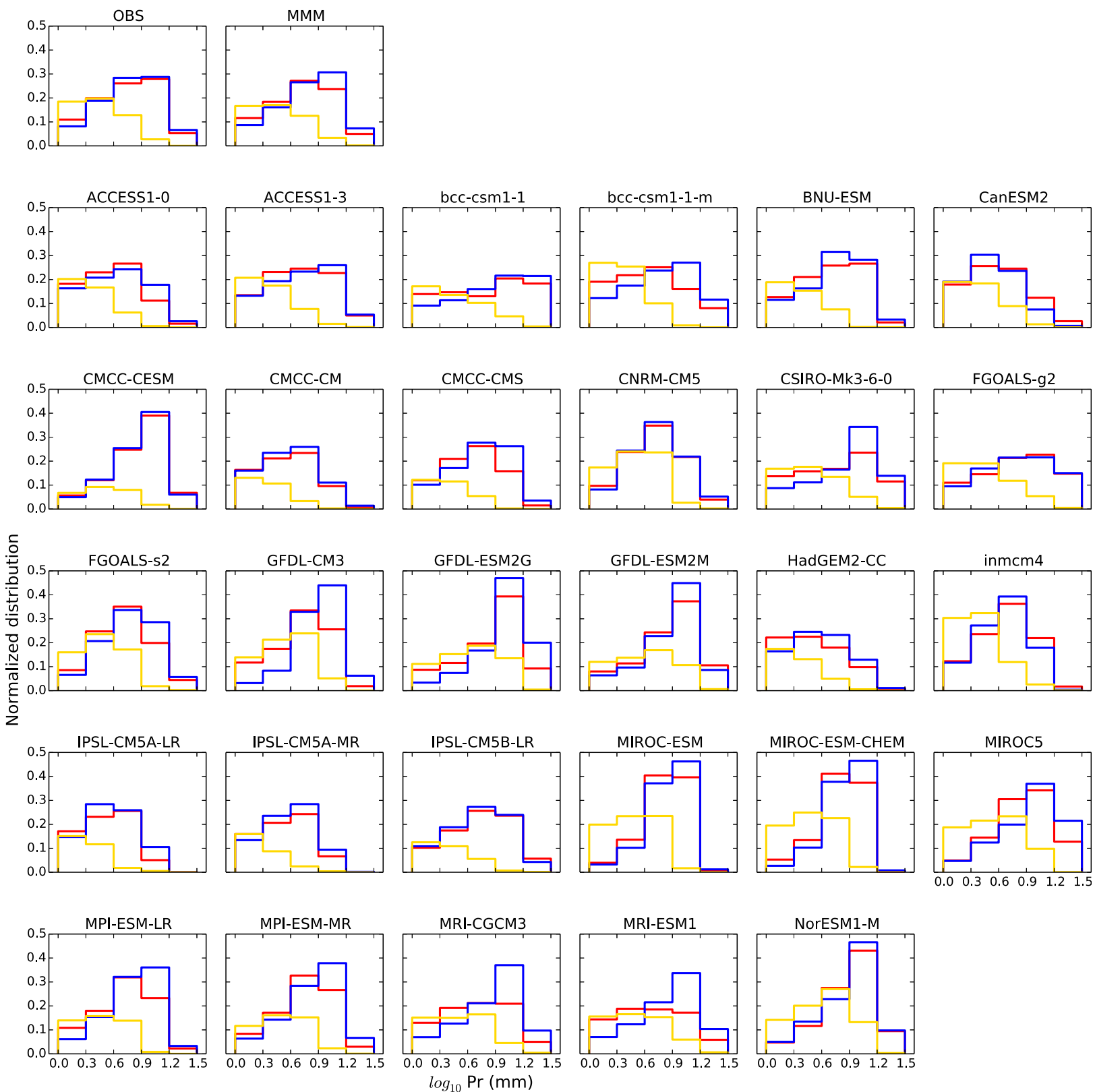

FIG. 8. Normalized distributions of $\log _{10}$ precipitation from reanalysis (OBS), the multimodel mean (MMM), as well as for each individual model. The normalized distribution is plotted for the SF-burst category (red), all other bursts combined (blue), and nonburst days (yellow).

the strong midlatitude influence described here and in other previously discussed studies. However, spatial OLR composites presented in Narsey et al. (2017) do not show this feature very clearly. The coexistence of eastward- and westward-propagating tropical disturbances might provide a useful starting point for future work on the triggering of northern Australian wet season bursts.

The non-SF-type bursts are more closely related to the passage of the MJO over the Maritime Continent
(Narsey et al. 2017). Lag composites of OLR during bursts show an eastward-propagating negative anomaly in the reanalysis. In contrast, the CMIP5 models do not appear to simulate a strong eastward-propagating negative OLR anomaly, and there is poor agreement between the models on the OLR pattern (Fig. 11). No individual model simulates the anomalous OLR lagcomposite pattern found in the reanalysis (Table 2).

Since most models do not have a realistic MJO pattern (e.g., Hung et al. 2013), we would not expect many 

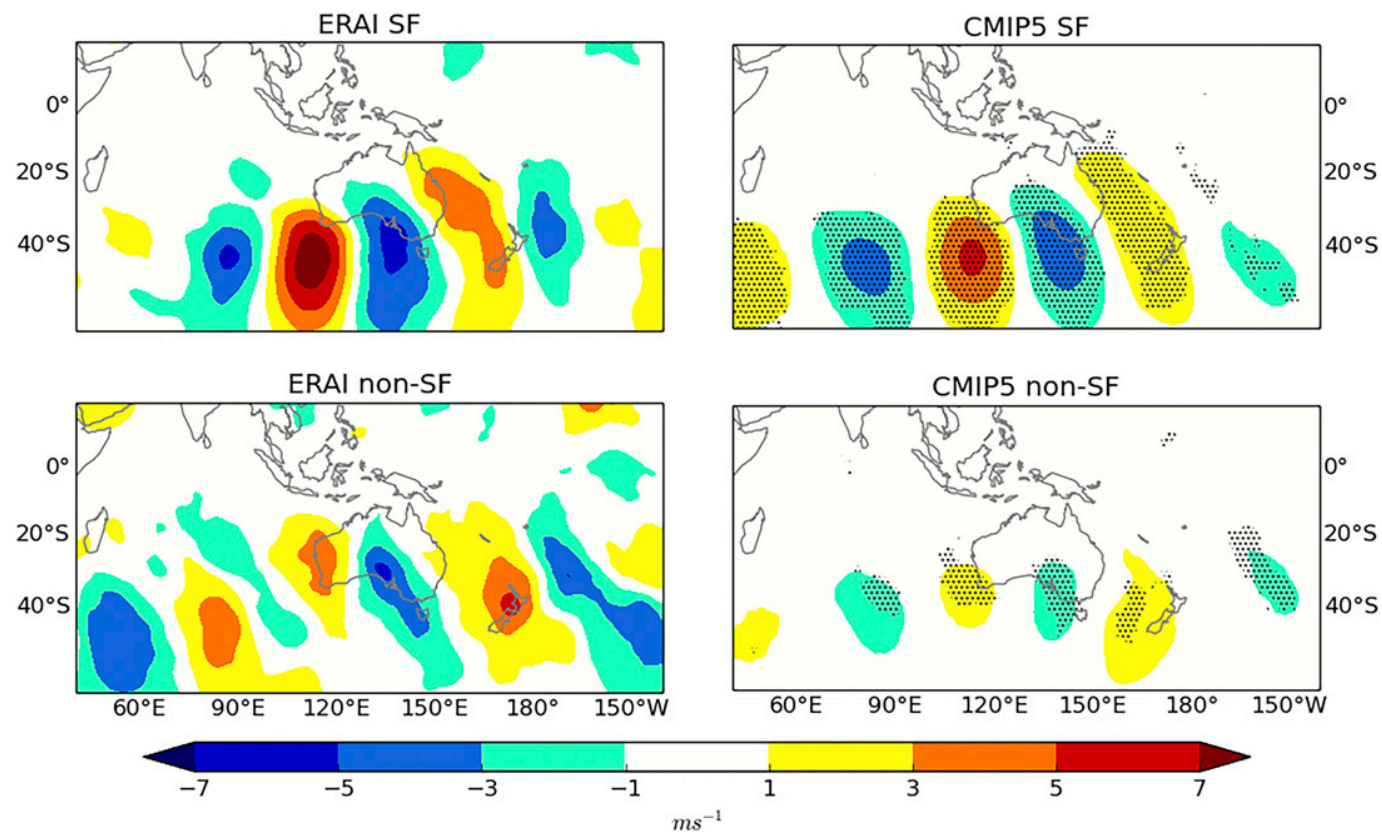

FIG. 9. Time-lag composites of 250-hPa meridional wind anomalies for all (top) SF bursts and (bottom) non-SF bursts, for (left) the reanalysis and (right) the multimodel mean. The composites shown are at two days prior to the burst. Stipples for the multimodel mean plots represent locations where over $80 \%$ of models agree on the sign of the anomaly.

models to simulate the temporal-spatial patterns found in the reanalysis. However, although their patterns are not consistent with reanalyses, some models simulate an eastward-propagating OLR anomaly associated with the composite non-SF burst (e.g., BCC_CSM1.1,
CMCC-CESM, and CNRM-CM5). It is possible that our choice of tropical convection proxy (OLR anomalies) does not best capture the MJO patterns in models. Ahn et al. (2017) found that CMIP5 models underestimate the amplitude of the MJO, particularly when assessed
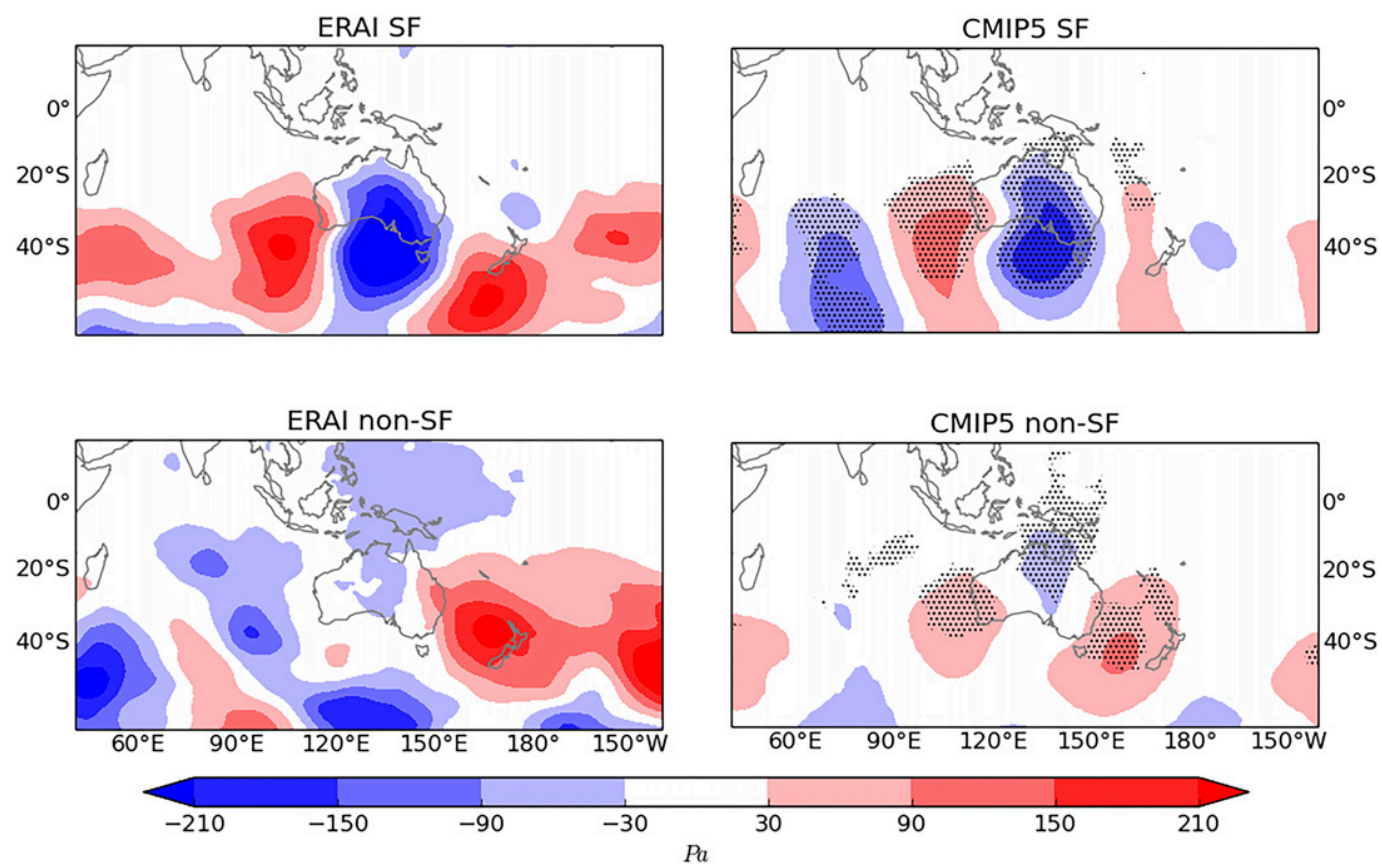

FIG. 10. As in Fig. 9, but for MSLP anomalies. 

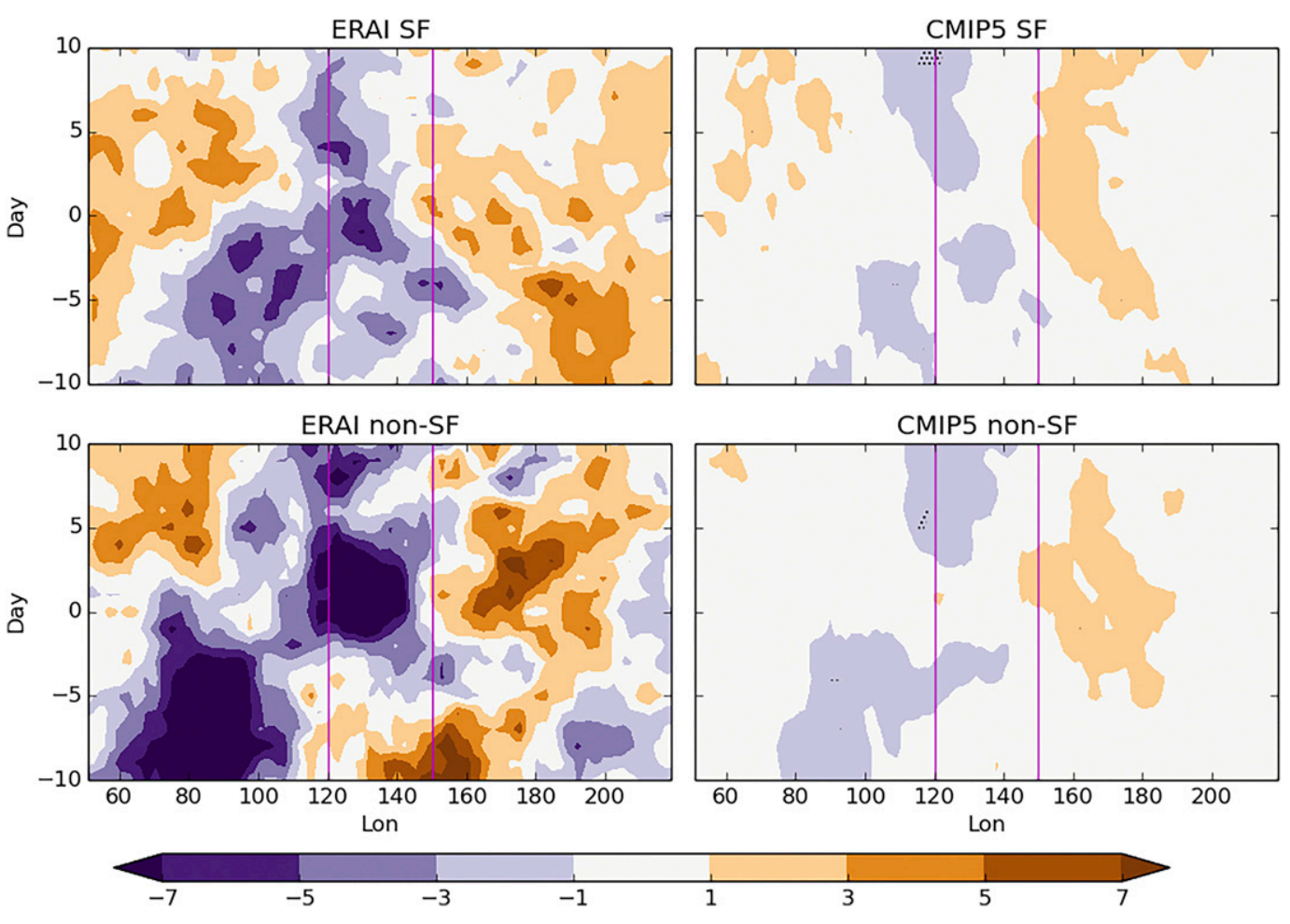

FIG. 11. Hovmöller plots of the lag composites of OLR anomalies for all (top) SF bursts and (bottom) non-SF bursts, for (left) the reanalysis and (right) the multimodel mean. OLR is meridionally averaged between $10^{\circ} \mathrm{S}$ and $10^{\circ} \mathrm{N}$. The ordinate shows days relative to the composite burst, while the abscissa shows longitude. Stipples for the multimodel mean plots represent time-longitudes where over $80 \%$ of models agree on the sign of the anomaly.

using OLR. They also found that the phase speed of the MJO in models was too high [directly contradicting the previously discussed results of Hung et al. (2013)], and the eastward-propagating convection was not coherent with the wind fields in the models. An alternate view of the MJO in CMIP5 models is proposed by Ling et al. (2017). By tracking individual MJO-like events, they found that all models were able to make MJO-like patterns, although these events depended on the background state (which they defined as precipitation, low-level zonal wind, and specific humidity) in the model. The frequency of occurrence of MJO-like events was then linked to the frequency of the appropriate background state in the model, which was not necessarily the same as the background state found in observations. Whether or not CMIP5 models produce an $\mathrm{MJO}$ for the right reasons, the results of the present study suggest that the models do not correctly simulate the observed connection between the MJO and the initiation of northern Australian wet season bursts.

By evaluating how well the CMIP5 models simulate a number of known features of northern Australian wet season bursts, we can determine the relative performance of individual models. However, this study finds that no individual model simulates all the evaluated aspects of the burst well. The midlatitude influence on northern Australian wet season bursts appears to be well simulated by CMIP5 models. Other influences on burst initiation, in particular the influence of the Madden-Julian oscillation, do not appear to be simulated well by the models. This result is reflected in the frequency bias of these types of bursts, as well as errors in the temporal-spatial patterns in the model burst composites. Nevertheless, the consistently accurate representation of the midlatitude influence on northern Australian wet season bursts in CMIP5 models is encouraging. Climate change projections of the Southern Hemisphere largescale circulation and its associated variability could potentially be used to improve the currently uncertain projections of the northern Australian wet season.

Acknowledgments. This research was supported by the Australian Research Council Centre of Excellence for Climate Systems Science (CE1101028). AWAP data were provided by the Australian Bureau of Meteorology. ERA-Interim data were provided by the European Centre for Medium-Range Weather Forecasts. We acknowledge the World Climate Research Programme's Working Group on Coupled Modelling, which is responsible for CMIP, and we thank the climate modeling groups (listed in Table 1 of this paper) for producing and 
making available their model output. For CMIP, the U.S. Department of Energy's Program for Climate Model Diagnosis and Intercomparison provides coordinating support and led development of software infrastructure in partnership with the Global Organization for Earth System Science Portals.

\section{REFERENCES}

Ahn, M.-S., D. Kim, K. R. Sperber, I.-S. Kang, E. Maloney, D. Waliser, and H. Hendon, 2017: MJO simulation in CMIP5 climate models: MJO skill metrics and process-oriented diagnosis. Climate Dyn., 49, 4023-4045, https://doi.org/10.1007/ s00382-017-3558-4.

Berry, G. J., and M. J. Reeder, 2016: The dynamics of Australian monsoon bursts. J. Atmos. Sci., 73, 55-59, https://doi.org/ 10.1175/JAS-D-15-0071.1.

Brown, J. R., R. A. Colman, A. F. Moise, and I. N. Smith, 2013: The western Pacific monsoon in CMIP5 models: Model evaluation and projections. J. Geophys. Res. Atmos., 118, 12 458-12 475, https://doi.org/10.1002/2013JD020290.

— A. F. Moise, R. Colman, and H. Zhang, 2016: Will a warmer world mean a wetter or drier Australian monsoon? J. Climate, 29, 4577-4596, https://doi.org/10.1175/JCLI-D-15-0695.1.

$\longrightarrow$ - — and R. A. Colman, 2017: Projected increases in daily to decadal variability of Asian-Australian monsoon rainfall. Geophys. Res. Lett., 44, 5683-5690, https://doi.org/10.1002/2017GL073217.

Christensen, J. H., and Coauthors, 2013: Climate phenomena and their relevance for future regional climate change. Climate Change 2013: The Physical Science Basis, T. F. Stocker et al., Eds., Cambridge University Press, 1217-1308, http://www.ipcc.ch/pdf/ assessment-report/ar5/wg1/WG1AR5_Chapter14_FINAL.pdf.

Colman, R. A., A. F. Moise, and L. I. Hanson, 2011: Tropical Australian climate and the Australian monsoon as simulated by 23 CMIP3 models. J. Geophys. Res., 116, D10116, https:// doi.org/10.1029/2010JD015149.

Danielsen, E. F., 1993: In situ evidence of rapid, vertical, irreversible transport of lower tropospheric air into the lower tropical stratosphere by convective cloud turrets and by larger-scale upwelling in tropical cyclones. J. Geophys. Res. Atmos., 98, 8665-8681, https://doi.org/10.1029/92JD02954.

Davidson, N. E., K. J. Tory, M. J. Reeder, and W. L. Drosdowsky, 2007: Extratropical-tropical interaction during onset of the Australian monsoon: Reanalysis diagnostics and idealized dry simulations. J. Atmos. Sci., 64, 3475-3498, https://doi.org/10.1175/JAS4034.1.

Dee, D. P., and Coauthors, 2011: The ERA-Interim reanalysis: Configuration and performance of the data assimilation system. Quart. J. Roy. Meteor. Soc., 137, 553-597, https://doi.org/10.1002/qj.828.

Drosdowsky, W., 1996: Variability of the Australian summer monsoon at Darwin: 1957-1992. J. Climate, 9, 85-96, https://doi.org/ 10.1175/1520-0442(1996)009<0085:VOTASM > 2.0.CO;2.

Flato, G., and Coauthors, 2013: Evaluation of climate models. Climate Change 2013: The Physical Science Basis, T. F. Stocker et al., Eds., Cambridge University Press, 741-866, http://www.ipcc.ch/pdf/ assessment-report/ar5/wg1/WG1AR5_Chapter09_FINAL.pdf.

Haynes, P. H., and M. E. McIntyre, 1987: On the evolution of vorticity and potential vorticity in the presence of diabatic heating and frictional or other forces. J. Atmos. Sci., 44, 828-841, https://doi.org/ 10.1175/1520-0469(1987)044<0828:OTEOVA $>2.0 . C O ; 2$.

Hendon, H. H., and B. Liebmann, 1990: The intraseasonal (30-50 day) oscillation of the Australian summer monsoon. J. Atmos. Sci., 47,
2909-2924, https://doi.org/10.1175/1520-0469(1990)047<2909: TIDOOT $>2.0 . \mathrm{CO} ; 2$.

Holland, G. J., 1986: Interannual variability of the Australian summer monsoon at Darwin: 1952-82. Mon. Wea. Rev., 114, 594-604, https://doi.org/10.1175/1520-0493(1986)114<0594: IVOTAS $>2.0 . \mathrm{CO} ; 2$.

Hung, M.-P., J.-L. Lin, W. Wang, D. Kim, T. Shinoda, and S. J. Weaver, 2013: MJO and convectively coupled equatorial waves simulated by CMIP5 climate models. J. Climate, 26 , 6185-6214, https://doi.org/10.1175/JCLI-D-12-00541.1.

Jones, D. A., W. Wang, and R. Fawcett, 2009: High-quality spatial climate data-sets for Australia. Aust. Meteor. Oceanogr. J., 58, 233-248, https://doi.org/10.22499/2.5804.003.

Jourdain, N. C., A. Sen Gupta, A. S. Taschetto, C. C. Ummenhofer, A. F. Moise, and K. Ashok, 2013: The Indo-Australian monsoon and its relationship to ENSO and IOD in reanalysis data and the CMIP3/CMIP5 simulations. Climate Dyn., 41, 30733102, https://doi.org/10.1007/s00382-013-1676-1.

Keenan, T. D., and L. R. Brody, 1988: Synoptic-scale modulation of convection during the Australian summer monsoon. Mon. Wea. Rev., 116, 71-85, https://doi.org/10.1175/ 1520-0493(1988)116<0071:SSMOCD >2.0.CO;2.

Liebmann, B., 1996: Description of a complete (interpolated) outgoing longwave radiation dataset. Bull. Amer. Meteor. Soc., 77, 1275-1277, https://doi.org/10.1175/1520-0477-77.6.1274.

Ling, J., C. Zhang, S. Wang, and C. Li, 2017: A new interpretation of the ability of global models to simulate the MJO. Geophys. Res. Lett., 44, 5798-5806, https://doi.org/10.1002/2017GL073891.

McBride, J. L., 1983: Satellite observations of the Southern Hemisphere monsoon during winter MONEX. Tellus, 35A, 189-197, https://doi.org/10.3402/tellusa.v35i3.11432.

Moise, A. F., R. A. Colman, and J. R. Brown, 2012: Behind uncertainties in projections of Australian tropical climate: Analysis of 19 CMIP3 models. J. Geophys. Res., 117, D10103, https:// doi.org/10.1029/2011JD017365.

Narsey, S., M. J. Reeder, D. Ackerley, and C. Jakob, 2017: A midlatitude influence on Australian monsoon bursts. J. Climate, 30, 5377-5393, https://doi.org/10.1175/JCLI-D-16-0686.1.

Raphael, M. N., and M. M. Holland, 2006: Twentieth century simulation of the Southern Hemisphere climate in coupled models. Part 1: Large scale circulation variability. Climate Dyn., 26, 217-228, https://doi.org/10.1007/s00382-005-0082-8.

Raymond, D. J., S. Gjorgjievska, S. Sessions, and Ž. Fuchs, 2014 Tropical cyclogenesis and mid-level vorticity. Aust. Meteor. Oceanogr. J., 64, 11-25, https://doi.org/10.22499/2.6401.003.

Sperber, K. R., H. Annamalai, I.-S. Kang, A. Kitoh, A. Moise, A. Turner, B. Wang, and T. Zhou, 2013: The Asian summer monsoon: An intercomparison of CMIP5 vs. CMIP3 simulations of the late 20th century. Climate Dyn., 41, 2711-2744, https://doi.org/10.1007/s00382-012-1607-6.

Taylor, K. E., R. J. Stouffer, and G. A. Meehl, 2012: An overview of CMIP5 and the experiment design. Bull. Amer. Meteor. Soc., 93, 485-498, https://doi.org/10.1175/BAMS-D-11-00094.1.

Troup, A. J., 1961: Variations in the upper tropospheric flow associated with the onset of the Australian summer monsoon Indian J. Meteor. Geophys., 12, 217-230.

Wheeler, M. C., and J. L. McBride, 2005: Australian-Indonesian monsoon. Intraseasonal Variability in the Atmosphere-Ocean Climate System, W. K. M. Lau and D. Waliser, Eds., Praxis, 125-173. , H. H. Hendon, S. Cleland, H. Meinke, and A. Donald, 2009: Impacts of the Madden-Julian oscillation on Australian rainfall and circulation. J. Climate, 22, 1482-1498, https:// doi.org/10.1175/2008JCLI2595.1. 